\title{
Pretense as alternative sense-making: a praxeological enactivist account
}

\author{
Martin Weichold ${ }^{1} \cdot$ Zuzanna Rucińska $^{2}$
}

Accepted: 26 August 2021 / Published online: 8 September 2021

(C) The Author(s) 2021

\begin{abstract}
The project of this paper is to synthesize enactivist cognitive science and practice theory in order to develop a new account of pretend play. Pretend play is usually conceived of as a representationalist phenomenon where a pretender projects a fictional mental representation onto reality. It thus seems that pretense can only be explained in representationalist terms. In this paper, we oppose this usual approach. We instead propose not only new explanatory tools for pretend play, but also a fundamental reconceptualization of the phenomena of pretend play, that is, of the very explanandum of theories of pretense. To do so, we suggest combining the turn to action and embodiment in the cognitive sciences with the practice turn in the humanities. From our point of view, pretend play has to be seen in its role in human life as a whole, which is to help children to learn to master the complex sociocultural contingencies of the manifold social practices that make up social reality. Pretend play should therefore be conceived as alternative sense-making that is always related, in varying ways, to ordinary social practices. Pretenders do not need to project mental representations onto reality, but make sense of their surroundings in different ways than encultured adults in ordinary practices. In the paper, we spell out this view and show how it enables an enactivist reconceptualization of imagination, intentions and knowledge, which are usually thought of as being available only to representationalist accounts of pretense.
\end{abstract}

Martin Weichold

martin.weichold@ur.de

Zuzanna Rucińska

zuzannaaleksandra.rucinska@uantwerpen.be

1 Institute of Philosophy, University of Regensburg, Universitätsstr. 31, 93053 Regensburg, Germany

2 Centre for Philosophical Psychology, University of Antwerp, Rodestraat 14, 2000 Antwerp, Belgium 


\section{Introduction}

Consider the following characterization of pretense:

Pretense is one of the earliest symbolic activities of young humans. In pretending, a child projects a mental representation onto reality, in a spirit of fun; the projection is done intentionally and with full awareness, and is often (but not always) accompanied by activities [1]. For example, a boy might take a stick and project onto it his mental representation of a horse, proceeding to "gallop" around with the stick. [...] Pretense involves distortions of the real world. If a young child reads a pretense event literally, his or her developing representations of the real world might get confused [8]. Thus, it is vital that young children interpret pretense in its nonliteral mode and distinguish it from what is real. [...] Pretense acts differ from real ones in both underlying intentions and external manifestations (Ma \& Lillard, 2013: 1).

This characterization of pretense, provided by psychologists Lili Ma and Angeline Lillard at the beginning of their article, seems to be an innocent articulation of a common-sense notion of pretense. Of course, children engaging in pretend play have to, on the one hand, immerse themselves into the pretend play, while avoiding to assume, on the other hand, that what holds in the context of pretense holds in other contexts as well. For instance, if the boy's grandfather reclaimed the stick and used it in its proper function as a walking stick, it would be rather surprising if the boy in all seriousness accused his grandfather of animal mistreatment. It thus suggests itself to express this common-sense knowledge by saying that the boy is able to distinguish the reality of the walking stick from the mental representation of a horse which he mentally projects onto it. And it suggests itself to say that what enables the boy to distinguish reality from pretense are, at least to some part, his intentions and full awareness by means of which he explicitly thinks of the pretense as pretense, so that he does not confuse it with reality.

It may then seem that pretense is a representational phenomenon: by its very definition, pretense seems to consist of a projection of a mental representation onto a reality, either in imagination (Kind, 2013; Picciuto \& Carruthers, 2016), intention (Rakoczy et al., 2005), or in cognitive architectures responsible for quarantining knowledge of fact and fiction (Nichols \& Stich, 2009). It is no wonder that most theorists have explained pretense mostly in terms of representational models, ranging from meta-representational (Leslie, 1987) to even "behaviorist" and action-oriented models of pretense (Perner, 1993; Harris et al., 1993; Currie, 2004; Picciuto \& Carruthers, 2016), which, though they focus on explicit action as a key feature of pretense, still define pretense as requiring mentally representing one thing as though it is another, through imagination, simulation or supposition (see Rucińska, 2016, 2017). By contrast, an explanation of pretense by $4 \mathrm{E}$ cognitive science would be a non-starter. At least parts of $4 \mathrm{E}$ cognitive science such as enactivism hold that some cognition does not, in essence, consist in the manipulation of contentful mental representations (Varela et al., 1991; Hutto 
\& Myin, 2013). Yet if the very phenomenon of pretense is representational, how could there be a non-representational explanation of it?

In this paper, we will still provide an enactivist account of pretense. But we will not attempt to provide a non-representational explanation of a representational phenomenon. Rather, we will argue that pretense is not a mental representational phenomenon in the first place, at least not in the sense of "representations" discussed in Section 4. ${ }^{1}$ We will thus propose an enactivist reconceptualization of the explanandum of pretense. According to our reconceptualization, all phenomena of pretense (1) consist of in alternative sense-making, and (2) are in varying ways related to ordinary social practices. These two characteristics are central for all phenomena of pretense and express what lies, in our view, at the core of pretense, without determining the concept of pretense. The details of our view will be spelled out below.

We admit that certain advanced forms of pretending entail that the pretender explicitly thinks of her pretense as pretense. But this is not true of the core of pretend play, found in the play of young children. Moreover, we propose that even the advanced cases of pretend play are explainable in terms of enactivism. In other words, we hold that what might look like harmless and innocent characterization of pretense as shown in Ma and Lillard's quote is not that harmless and innocent after all - it is suggestive of a representation-hungry approach to pretense and makes use of terminology that can easily be interpreted as cognitively loaded. ${ }^{2}$

For instance, should one, on reflection, really think of pretense as projection of a mental representation onto a reality? Is the very dichotomy between a mind-independent reality and imaginative projections really helpful? Should one think of the pretender as always acting with "intention" and "awareness", and always in the spirit of fun? Is it really the case that even young children distinguish between pretense and non-pretense contexts in virtue of being mindfully aware of pretense as pretense? Our answers to all these questions are negative. We will explain our reasons for these answers in the course of the paper.

The paper will unfold as follows. Before proceeding in medias res, in Section 2 we will already provide a short overview of our alternative approach to pretend play, and contrast it with that of Ma and Lillard. Then, in Section 3, we will discuss a

\footnotetext{
${ }^{1}$ It is important to distinguish different senses of the term "representational". Enactivists do not take issue with the idea that something can serve as a representation, like a map or a picture. It is the notion of representation connected to the idea that all cognition consists in the processing of content that mirrors a mind-independent world that enactivists object to (see Varela et al., 1991). For the sake of clarity, we will refer to this latter notion of representation "mental representation". Mental representations are theoretical entities posited to explain intelligent behavior (Chemero, 2009). Understood as informationbearing structures that store mental contents with conditions of satisfaction, mental representations are often assumed to play a role in the context of pretense, where one object (X) stands for another (Y) by specifying the content (' $Y$ ').

2 To clarify, we do not accuse of Ma and Lillard of having made a severe theoretical mistake. What they say can be understood as their attempt to express common sense ideas towards pretense, and the way they express it might be just a façon de parler. However, such seemingly harmless conceptualizations sometimes lead to one-sided and problematic theories. For instance, saying that pretense requires intentional projection of a mental representation onto a reality suggests that it is a cognitively effortful task. Hence, it is worth examining such characterizations with critical care.
} 
foundational issue: we will argue that a convincing account of pretense should focus on describing and explaining the phenomena of pretense, instead of beginning with a conceptual analysis of the concept of pretense. With this issue clarified, in Section 4 we will provide the background for our enactivist reconceptualization of pretense by rehearsing key ideas of enactivist cognitive science and practice theory, and by showing how they can be fused. Against this background, Section 5 will show how we suggest to rethink the phenomena of pretense by means of our "praxeological enactivism". In Section 6, we will return to the representationalist opponent and address the question whether the invocation of imaginings, intentions and knowledge is still important for a proper analysis of pretense, before concluding the paper in Section 7.

\section{Our approach to pretend play: a preliminary sketch}

Let us provide a short overview of, and a motivation for, our alternative approach to pretend play. According to our reconceptualization, all phenomena of pretense (1) consist of in alternative sense-making, and (2) are in varying ways related to ordinary social practices. To explain: in pretend play, we bring forth a pretend reality by making new sense of our environment, a different sense than the sense we make when we typically engage with that environment, while that different way of making sense emulates other, existing ordinary social practices.

Our suggestion is motivated by the idea that there is no pre-given, mind-independent reality, or that human beings are detached individuals who cope in this reality by first mirroring it in their minds, and then by manipulating mental representations of it. Instead, whether they are engaged in pretense or not, human beings are always acting on a world which is already understood by them in a certain way (see Section 4).

Moreover, we propose that there is no essential difference between pretense and non-pretense in terms of one requiring special cognitive capacities or mechanisms that track fictions. In both pretense and non-pretense cases, humans bring forth, or enact, their surroundings as understood worlds. For instance, in reconsidering Ma \& Lillard's case of the boy playing with a stick as if it is a horse, we propose that a certain space is enacted by the boy as a prairie to be crossed on a horse. Enacting this situation requires from the boy to make different sense of the 'stick' than it is usually made sense of, but does not require having to represent the stick as 'pretend horse' first (see Sections 5 and 6 for details of our proposal). Consider the possibility that the boy's grandfather enacts the same space as a living room, where the same stick helps him to get from the couch to the TV. Of course, it is important to not confuse the two contexts. But not confusing different contexts is a task that is not special to pretense (see also Langland-Hassan, 2020). It is a task, which humans have to master all the time in everyday life, because they play different social roles in different social practices.

These practices constitute our social reality. If it comes to court proceedings, the court will judge that the stick is actually a walking stick legally owned by the grandfather. But this does not mean that perceiving the stick as walking stick is not 
a matter of enaction, importantly similar to the enaction of the stick as a "horse". There are, to be sure, important differences between the enaction of a world in the context of an ordinary social practice and the enaction of a world in the case of pretense. However, we contend that these differences should be understood against the background of the commonalities. To pretend means to make sense of one's surroundings in an alternative way, crucially varying from how the world is perceived in the context of ordinary practices. In other words, it is a core feature of pretense that the pretender makes alternative sense of her surroundings, where the feature alternative is attributed from the perspective of an adult who participates in ordinary practices.

Consider another example of a young girl pretend playing to be a lion. According to our suggestion, she is enacting a certain narrative or a public script for lion play: lions find caves to hide into, or rocks to climb upon (see also Rucińska, 2016, 2019). Her play is spontaneously guided by the affordances of her environment as she is making sense of it while at play: the chair affords climbing on to, and therefore, "climbing a rock" play, while the table affords hiding under, therefore, "hiding in the cave" play, etc. If the girl's mother interrupts the play because the dinner is ready, the girl can switch from play context to non-play context smoothly: the chair turns back into something to sit on, while the dinner table is again the place to eat dinner.

According to our suggestion, it is not the case that the kitchen table is always "really" or "truly" a kitchen table - by standard definition a piece of furniture providing a surface for eating - and in order to pretend play that it is something else, e.g., a lion's cave, we must bypass this "true meaning" of the kitchen table and project a new meaning onto it by means of fictional mental representations. Rather, we find ourselves most often in situations where we make sense of the kitchen table while we are participating in the ordinary social practice of having dinner. In the context of play, however, we make sense of the kitchen table in an alternative way. There is no independent reality that needs to be represented in the mind "as pretense" in order to engage in pretense; we propose that we enact our realities instead (see Section 4 for further argument).

With this roughly sketched proposal, we aim to show how 4E philosophy and cognitive science can shed new light on the phenomena of pretense. We aim in particular to show how enactivism can be helpful in this regard. And in this paper, we will rely in particular on some of the initial ideas of enactivism that have originally been proposed by Francisco Varela, Evan Thompson and Eleanor Rosch in their book The Embodied Mind (1991, reissued 2017). So far, there has not been much work on pretense from the perspective of enactivism aside the works of Hutto (2015), Gallagher (2017), and Rucińska (2014, 2016, 2019), and we consider the proposal made here to be consistent with and a helpful addition to this earlier work.

What is more, we propose that connecting enactivism to practice theory is fruitful not just for an enactivist account of pretense, but for the development of enactivism per se. Practice theory, or praxeology, is an umbrella term to unite common underlying ideas in the works of thinkers such as Wittgenstein, Heidegger, Bourdieu, Giddens, Butler and Schatzki. We will specifically focus on Bourdieu 's philosophy, including his concept of habitus, to understand pretense (see Section 4). Thus, there is not only an "action turn" in the cognitive sciences, as defended by enactivists, but 
also a "practice turn" in the humanities (proclaimed by Schatzki et al., 2001), which can further impact cognitive science as well. As we will show with the example of pretense, it is fruitful for the proponents of both turns to join forces, as this allows better understanding of the nature of pretense, the nature of the mind of the pretender, and the wide reach of enactivist explanations.

\section{Doing without the concept of pretense}

In this section we aim to justify our starting point: one should focus on the phenomena of pretense instead of an analyzing of the concept of pretense or determining its necessary and sufficient conditions.

Many researchers start with the everyday concept of pretense (Anscombe, 1958; Austin, 1958), or with everyday lay theories of pretense (Lillard, 1993), which propose to define pretense through necessary and sufficient criteria (see also LanglandHassan's (2020) scientific explanatory proposal that focuses on first establishing necessary and sufficient conditions for pretense). Elizabeth Anscombe and John Austin, for instance, define pretense as concealing or suppressing something, or "trying to appear what you are not" (Anscombe, 1958, 283), following the Latin term prae-tendere, which stands for "holding or stretching one thing in front of another in order to protect or conceal or disguise it" (Austin, 1958, 267). Austin has engaged in an elaborate analysis of the concept of pretense, by analyzing the meaning of the verb "pretending", looking at the difference between pretending to vs pretending that, and to the difference between the constructions "pretend to A" vs. "pretend to be A-ing" $(1958,265) .{ }^{3}$ From that analysis he concludes that the essence of pretense is to "disguise some reality, often some real behaviour" (270) and that pretending should be seen in general as "not exactly doing things" (278). His reason for the broadness of that characterization is that his conceptual analysis shows the many differences and exceptions to the rules he aims at establishing about "pretense". However, even Austin $(1958,278)$ admits at the end of his analysis that the differences between what counts as pretense vs. what does not might not be so important after all; they are only interesting to philosophers who are interested in finding a "proper place" for the concept of pretense within a family of related concepts.

By contrast, we deliberately avoid this alternative starting point. The first reason for this is that conceptual analyses are not necessary to achieve scientific progress or engage in empirical investigations. For instance, the notions of "gene" or "species" are functioning terms in biology, even though they do not have consistent definitions (Dennett, 2020) and do not invoke a detailed conceptual analysis to elucidate scientific research. Dennett's point is that we don't need well-defined concepts for good scientific work, which could also hold for the concept "pretense".

\footnotetext{
${ }^{3}$ For instance, pretending to play chess differs from pretending to be playing chess in that in the former case one is not actually playing chess, whereas in the latter case one can be playing chess, but through that action intends to do something else (ibid., 271).
} 
However, we would like to point out that should one want to work with a welldefined concept to guide scientific research, then orienting oneself on the concepts from ordinary language, aside being a difficult task due to many disagreements on how to best conceptualize pretense (see, for example, Anscombe's (1958) critique of Austin's conceptual analysis), is not the right way to go. Science often needs more special, rigorous concepts than those found in folk psychology. For instance, the English concept of "sunrise" (the time in the morning when the sun appears) is perfect for everyday use, but provides less than useful guidance for an astronomer and her serious scientific investigation of the respective phenomenon (the "instant in the morning under ideal meteorological conditions, with standard refraction of the Sun's rays"), and of how it works ("when the upper edge of the sun's disk is coincident with an ideal horizon"). ${ }^{4}$ Thus, there is no good reason why a cognitive scientist working on pretense should work with a concept of "pretense" as found in ordinary language.

Secondly, as we will show in this paper, the phenomena of pretend play under investigation do not have sharp logical boundaries, but naturally overlap with many forms of non-pretend, exploratory play, and many non-pretend, ordinary engagements in social practices. For instance, some children might pretend with deliberate intention to enact $\mathrm{X}$ as $\mathrm{Y}$, but others might spontaneously find new affordances to pretend play provided by their toys, or be interpreted as pretending by their friends and thereby invited to further enact what did not start off as a pretend scenario. Starting with a conceptual analysis of pretense yields the danger of assuming that all instances of pretense work in a uniform way, while there are in fact many differences and variations of pretend play.

Thirdly, Western ordinary language is arguably strongly influenced by specific assumptions that can be explained with reference to its cultural history. For example, according to Henrich (2020), Christianity had a huge influence in shaping Westerners' assumptions about their minds in individualistic and intellectualistic ways. Any theory of pretense which starts with a conceptual analysis of the English concept "pretense" thus runs the danger of repeating and reifying the intellectualistic and individualistic assumptions built into Western ordinary languages, for instance, the assumption of analyzing human action in terms of underlying intentions, as seen in Austin's case. In this way, a conceptual analysis of pretense would also miss out the crucial interactive dynamics of pretend play, dynamics which praxeological enactivism is much better equipped to investigate.

This is why we think that an analysis of the concept of pretense in terms of necessary and sufficient conditions might not be all that helpful for understanding the real phenomena of pretense (though there are some situations, when the concept of pretense can be of relevance for the phenomena of pretense, which we will mention in Section 5.4). We will argue instead that all instances of pretense are characterized by alternative ways of sense-making and are related in varying

\footnotetext{
${ }^{4}$ Retrieved on 03.11.2020 from http://www.ga.gov.au/scientific-topics/astronomical/astronomical-defin itions\#heading-1
} 
ways to ordinary social practices, thus providing core features of pretense phenomena, without establishing what must and must not count as pretense.

To explain further what makes pretense special and distinguishes it from ordinary cases of sense-making in ordinary social practices, we will point in Section 5 to features that distinguish many instances of pretend play from engagements in ordinary social practices. We also acknowledge the many variations of pretense cases. We will thus aim to show that our account of pretense is informative and can potentially make a difference to empirical analyses of pretend play, even though we do not provide necessary and sufficient conditions for what counts as pretense. But before we can do so, we first turn to developing our "praxeological enactivist" account.

\section{Towards praxeological enactivism}

There are many ideas that are central for enactivist cognitive science and philosophy, but for the purposes of this paper, we will concentrate on an idea that lies at the heart of a classic work of enactivism, namely, Varela et al., (1991/2017) book The Embodied Mind. This idea, to start with a negative formulation, is that mind and world should not be conceived as separate entities that exist independently from each other. No doubt, this idea is quite a natural one. However, Varela et al. use a mix of empirical findings, philosophical arguments and Buddhist and phenomenological observations to show it is problematic. They express the problematic position by asking the question "Which came first, the world or the image?" (2017: 172), and propose two suggestive answers to this question:

Chicken position: The world out there has pre-given properties. These exist prior to the image that is cast on the cognitive system, whose task is to recover them appropriately (whether through symbols or global sub-symbolic states).

Notice how very reasonable this position sounds and how difficult it is to imagine that things could be otherwise. We tend to think that the only alternative is the egg position:

Egg position: The cognitive system projects its own world, and the apparent reality of this world is merely a reflection of internal laws of the system.

As the very names suggest, the chicken-egg-problem is a problem that should not be solved, but dissolved. Varela et al. therefore aim for

a middle path between the Scylla of cognition as the recovery of a pregiven outer world (realism) and the Charybdis of cognition as the projection of a pregiven inner world (idealism). These two extremes both take representation as their central notion: in the first case representation is used to recover what is outer; in the second case it is used to project what is inner. Our intention is to bypass entirely this logical geography of inner versus outer by studying cognition not as recovery or projection but as embodied action. (ibid.) 
Notice how the quote from Ma and Lillard embraces both the problematic chicken and the problematic egg position. When it comes to pretense, the quote adopts the egg position, and when it comes to non-pretense, the quote adopts the chicken position. The world "is" a certain way, which we directly perceive, and in pretense, we imaginatively project a fictional reality onto that world, while having to quarantine the fictional reality from the true reality all the same. This starting point resonates with other pretense theorists, including most recently Picciuto and Carruthers (2016), who propose that in banana-as-telephone pretense, one must "suppress the obvious tendency to see the object as a banana [true reality], and select the option of seeing it as a telephone [fictional reality] instead" (323, added parentheses).

It is possible, however, to walk a middle path between Scylla and Charybdis. As we understand it, this does not mean to deny that there are objective properties, as individuated by scientists from the perspective of the practice of science. For instance, physicists describe the world as composed of light waves of a certain wavelength. However, what humans experience and act on are always worlds that are understood by them, that are meaningful to them. Humans do not experience light of certain wavelengths, but colors.

This thought itself is not yet specific to enactivism, as several philosophers since Kant have argued for it (for instance, Heidegger (1962, §§31ff)). However, enactivism conceives of the process of our subjective understanding or the world, or sensemaking, in a distinct way. In its view, sense-making is not an intentional action of an autonomous individual or of a "transcendental subject", but is rather a biological and interactive process carried out by self-organizing systems (Varela et al., 1991). In Evan Thompson's words,

human cognition is not the grasping of an independent, outside world by a separate mind or self, but instead [it is] the bringing forth or enacting of a dependent world of relevance in and through embodied action (2017, xviii).

Enaction can thus be defined as the constant, interactive process through which an organism engages in sense-making, or interprets its surroundings as a meaningful world of relevance (cf. Weichold, 2018). This enacted dependent world of relevance exists only for this specific living body with its unique way of interpreting the environment against the background of its own self-organization and its history. Prior interactions with the understood world of relevance will always have shaped the living body, so that the way it brings forth or enacts its world at a particular moment can only be fully comprehended if one takes into view the history of that living body. Thus, mind and world specify each other mutually. How the living body enacts these surroundings as a dependent world of relevance depends on the living body's self-organization within its environment..$^{5}$

\footnotetext{
${ }^{5}$ One might question if enactivism denies the existence of objective surroundings, or mind-independent reality, altogether. Does the world disappear when we do not act on it? As already explained by means of the example of light of a certain wave length, enactivists would not go so far. Hence, the qualification needs to be made carefully. However, when an agent confronts a reality in daily life, it is never done from an objective perspective. Enactivists would agree here with phenomenologists that different persons or agents inhabit different lifeworlds in virtue of their embodied and sociocultural perspectives. Thanks to an anonymous reviewer for the phrasing.
} 
This can include the social environment. Back in 1991, Varela and colleges mentioned the importance of culture and sociality for understanding human behavior, but they have not developed a specific enactivist account of it. This has changed in the meantime, as there are now various enactivist accounts of different dimensions of culture and sociality (cf. van Dijk \& Rietveld, 2017; De Jaegher \& Di Paolo, 2007; Di Paolo et al., 2018; Rucińska, 2017, 2019; Weichold, 2016, 2017). That said, we propose that enactivism's capacity to explain sense-making in social contexts (as, we will show, is the case for explaining pretense), can be further enhanced if it is teamed up with the "practice turn" in the humanities. To our mind, praxeology provides further and new explanatory resources which can complement enactivist explanations in new and important ways.

We thus suggest synthesizing enactivism with practice theory. Just as we concentrated on the work of Varela, Thompson and Rosch and not the whole field of enactivism, we will place the work of Pierre Bourdieu (2000) at the center of our presentation of practice theory. Bourdieu's ideas are, in the respects that are of importance for this paper, very similar to the ideas of enactivism, but they are also tailored to focus on the social and cultural dimensions of human existence. ${ }^{6}$ Just like enactivism, Bourdieu emphasizes that humans always live in and act on a meaningful, understood world. And just like enactivism, Bourdieu assumes that mind and world specify each other mutually and have to be understood in relation to each other (2000: 135).

What practice theory adds, however, is that the environment humans find themselves thrown into is always already a social environment consisting of social practices. Practice theory emphasizes that human actions are social through and through, even if there is only one human being who carries them out (cf. Steiner \& Stewart, 2009). ${ }^{7}$ For example, a professor's action of writing a single-authored paper performed alone at her desk is still a social one, because it is constituted by shared social rules for writing a paper, is addressed to a yet unspecified readership, and in general "clings into" and carries on the social practice of writing academic papers (cf. Steiner \& Stewart, 2009). Practice theory views human actions as performances, where each performance re-enacts prior performances of "the same" action. ${ }^{8}$ For instance, writing a paper makes sense to the professor only because "writing a paper" exist as a professional act, and because it is, within the academic culture, understood as an action constituted by the university policy and its rules. It is thanks

\footnotetext{
6 The similarity and compatibility of these two at first sight seem rather different, but both have roots in hermeneutic phenomenology.

7 It is here that practice theory departs from the point of view of classical enactivism. According to Varela et al., a single bacterium might enact some molecules as nutrition and move towards them. The nutrition exists then in the lonely world of the bacterium, and the bacterium needs no one else for its biological behavior of moving towards its meal. A bacterium can manifest behavior in a completely lonely way, while human actions are virtually always social, even when humans act alone.

8 While there are action types that vary because they are performed at different times or in different contexts, they might be individuated as being part of the "same" social practice, depending on the theoretical interest of the theorist.
} 
to this shared history of social (academic) practices that the present performance is intelligible to others, and even to the performing agent herself.

We suggest calling the history of all performances of "the same" action a social practice. According to Bourdieu (2000), humans are able to successfully participate in social practices not because they represent explicit social rules accurately in their minds and then follow them intentionally. Rather, their constant exposure to social practices has shaped their dispositions for interpreting their surroundings. Bourdieu (2000) famously coined the term habitus for those socially shaped dispositions for making sense of the world. Against the background of this habitus formation, that is, of the social shaping of their dispositions for sense-making, humans are able to enact their surroundings as inviting behavior that is socially appropriate for the practice they are at the moment engaging in. In other words, they develop a practical knowledge or "bodily know-how" to react skillfully to subtleties in their sociomaterial environment. Their attunement to rule-structured social practices shapes how they enact their surroundings. We will illustrate this in more detail below, when we utilize practice theory for explaining pretense.

Taken together, Varela's enactivism and Bourdieu's practice theory will prove to be the perfect team for rethinking the explanandum of pretense. Varela's enactivism allows us to analyze the nature of sense-making as an embodied and biological process better than any other theory, including pretense theories that propose the need to invoke a representational state of mind. Practice theory can further elaborate on how human sense-making is nearly always shaped by social practices - even in the case of pretend play that is creative or performed alone. Both theories can be brought together to show that human beings are at essence sense-making organisms who continuously enact worlds of practical relevance. And since human beings are social beings, their enactment of worlds usually takes place in the context of social practices. We will call the resulting fusion of enactivism and practice theory "praxeological enactivism", and show, in what follows, how the nature of pretense can be understood against this background.

\section{Rethinking pretense in light of praxeological enactivism}

Against the background of the previous points, we want now to present our reconceptualization of pretense from the perspective of praxeological enactivism. To our mind, there is not just one unitary phenomenon of pretense, but a whole family of interrelated phenomena. It would be a misinterpretation of ordinary language to think that there is exactly one phenomenon of pretense just because there is the one word "pretense" in the English language. The pretense phenomena can be comprehended best if one appreciates both the commonalities found between the phenomena, as well as their differences.

According to our reconceptualization, there are two points that are central for all phenomena of pretense, as already alluded to in the introduction. First, it is characteristic of all phenomena of pretense that they consist in alternative sensemaking. Second, it is characteristic of all phenomena of pretense that they are - in varying ways - related to and interwoven with ordinary social practices. These two 
characteristics express what lies, in our view, at the core of pretense. But, as we discussed in Section 3, they should not be conceived as necessary and sufficient conditions of an analysis of the concept of pretense. We are interested in characterizing the phenomena of pretense and explaining how they work.

In this central section, we will first embed our proposal in an analysis of the role of pretense in human life (Section 5.1). Against this background, we will discuss the just mentioned two core characteristics of pretend play (Section 5.2). While we will point to the relations of instances of pretend play to ordinary engagements in social practices, we will in the following section show how our praxeological enactivism can also point to crucial differences between pretend play and ordinary social practices (Section 5.3). We will also illustrate how usages of the concept of pretense can in rare cases influence phenomena of pretense (Section 5.4).

\subsection{The role of pretense in human life}

To begin with, it is helpful to reflect on the role of pretense in human life. Though pretense is carried out by adults in various contexts (such as in acting or deception), the most enthusiastic pretenders are children in the context of play. This is not an accident. Radu Bogdan (2005) has defended the following view:

$[\mathrm{P}]$ retend play develops as an adaptive strategy in early childhood in response to pressures on the young mind to assimilate and master such cultural novelties. So construed, then, pretend play is a solitary or interpersonal initiation of the young child into the ways of adult society and culture - a playful and often creative exercise in cultural conformity (ibid.: 192).

This suggestion makes a lot of sense against the background of practice theory. If children could just perceive and represent reality, as it is suggested by the quote from Ma and Lillard, adapting to social reality would be easy, and engaging in pretend play would not be all that necessary. However, if practice theory is right and human life consists of a multitude of social practices, learning to adapt to all these different practices might be challenging for children. In particular, children have to learn that there is a variety of social practices, and how one behaves "correctly" in one practice is different from how one behaves "correctly" in another. The re-enactment of observed behaviors and creation of a play context where one can explore them becomes the right platform for learning and exploring (and sometimes even negotiating) the rules of social conduct. As human social reality consists of a variety of social practices with a variety of different social norms, young children have to learn to adapt to these changing conditions of what counts as "important" and "real" in different practices, and pretend play provides them a way to do that.

Pretend play presupposes the ability to make sense of one's surroundings in one particular context, while the same surroundings have a different meaning in another context. In our previously discussed example, the stick counts as a horse before lunch, but it counts as the grandfather's walking stick while the family takes a walk. It is social life itself which requires children to make different sense of the same surroundings in different contexts. What is more, human social practices are contingent. 
If children are to learn how to participate in them correctly, they have to master the respective socio-cultural contingencies (Weichold, 2016), that is, they have to understand which bodily behaviors have which social consequences. Bogdan illustrates a related point as follows:

Think of a child who impersonates an actor taking final bows in front of an appreciative adult partner. The child bows and the partner applauds (theme well captured), then bows too much and almost loses her balance, while the partner laughs heartily (ooops! wrong variation), regains composure and lifts her arms in a wide $\mathrm{V}$, à la Pavarotti, with partner applauding again (right variation), then keeps the arms too long in the air and partner laughs again (wrong variation), and so on (2005: 203).

In other words, it is crucial for human adults that they master successful participation in a variety of different social practices with complex social norms.

We thus propose to conceive of pretend play as an exercise of practicing being part of a social practice, even though children do not engage in pretend play with this deliberate goal. One might even speak of a practice practice: a practicing of participating in ordinary social practices. ${ }^{9}$ Pretend play might thus be seen as a tool or means to an end, which is mastering complex social norms and understanding others who partake in those norms. While ordinary social practices constitute particular ways of acting, thinking, and feeling (ways of "being-in-the-world"), that is, of interpreting one's surroundings and one's place in it, pretend play further helps young children to reshape their acting, thinking, and feeling, so that they become structured by ordinary social practices. Pretend play is in this sense part of a crucial social transformation of children's "being-in-the-world". At the same time, pretend playing provides new and intrinsically valuable experiences to the young players.

\subsection{The core characteristics of pretend play}

We will now elaborate on the two points that we deem are central for all phenomena of pretense: engaging in alternate sense-making, and relating to ordinary social practices.

Firstly, pretense is at its core a sense-making activity. A child engaged in pretend play enacts, or brings forth, a pretend world. This can be a world where teddy bears are interpreted as distinguished guests of a tea party, where bananas become phones, or where large t-shaped pieces of wood are enacted as the swords of honorable knights. This enaction happens, however, not only in pretend play. Many adults interpret, for instance, the large t-shaped pieces of wood as holy crosses, and hang them on their walls and pray to them. But this does not mean that the adults' enaction brings forth a "pretend world", nor that it is "truer" to a mind-independent reality than children's play. Rather, the adults who pray to the t-shaped pieces of wood

\footnotetext{
9 An observant reader may connect our word play to the famous "theory theory" found in the philosophical literature on understanding other minds. While our "practice practice" is a contender to replace "theory theory", a further comparison between these approaches is beyond the scope of this paper.
} 
make sense of those pieces of wood through a larger social, religious practice, most likely the same practice in which the woodworker who made the piece engaged. Similarly, children who play-fight with t-shaped pieces of wood make sense of them by referring to a less institutionalized social practice of playing "knights". Both seeing the t-shaped piece of wood as a holy cross and seeing it as a sword are results of sense-making.

The same holds for examples that are at first sight in tension with our analysis. An adult might say that the toy teacups at Lara's tea party with her teddy bears are empty in reality, and that Lara projects onto them a mental representation of teacups that are full of tea. However, we describe this example as Lara enacting the teacups as full in her tea party world. Her actions always happen in interaction with the affordances in her tea party world. Those affordances can be given by the materiality of the objects ("pick-up-ability" of a toy teapot) in relation to Lara's capacities (being able to lift it). They are also created in intersubjective contexts, together with other people (who are laughing and "tasting the tea", as opposed to frowning upon such play), and guided through enculturation in narrative practices of what one does with teacups (see Rucińska, 2016, 2017). Similar processes also happen at adult tea parties, when a cup of tea is perceived as oriental, rare and valuable. Such a perception is not the representation of properties of an objective reality (as explained in Section 4, the enactive and praxeological lifeworlds are not beholden to objective surroundings either). ${ }^{10}$ Instead, it is a perception of a situation as available to a tea lover with the right enculturation. In sum, it is a core feature of pretense that the pretender makes what looks like an alternative sense of her surroundings, where the feature "alternative" is attributed from perspective of a participant of ordinary practices.

Secondly, to fully understand pretense, it is important to see that it is always related to social practices, though different members of the family of pretense phenomena are related to social practices in different ways. To begin with, we wish to highlight that some episodes of pretend play can themselves be conceived in terms of social practices, at least in a wide and liberal understanding of "social practices". There can, for instance, be mildly institutionalized social practices of pretend playing "knights", and young children can learn to pretend play "knights" according to the rules of this pretend play practice. To be sure, there are still some crucial differences between pretend play practices and ordinary social practices, as we will argue in the next section - pretend play practices have normally no serious consequences in the wider social world, for instance. There are also instances of pretend play of a more spontaneous and creative sort, which we will discuss shortly, and these spontaneous actions can also be analyzed as instantiations of social practices. However, all instances of pretend play - from the most institutionalized to the most spontaneous and creative - are related in various ways to ordinary social practices, whether or not the pretend play itself can be appropriately analyzed in terms of social practices.

One of the many ways of how pretend play can be related to ordinary social practices is that many instances of pretend play emulate ordinary social

10 Thanks to an anonymous reviewer for this phrasing. 
practices. For instance, Lara's tea party emulates an adult's tea party. Pretend playing to be a shopkeeper and a customer at a grocery store emulates the social practice of grocery shopping. Pretend playing cooking emulates the practice of preparing lunch or dinner.

However, the family of pretense phenomena is divided. In some cases, the young pretenders have witnessed a performance of the ordinary social practice which they emulate, for instance a visit to the grocery store. The emulation need not be an exact reconstruction of their experiences. The "shopping" play also need not correctly represent the practice of shopping. It must only be good enough to satisfy the child's emotional and learning needs. There are also cases where the toys the children play with strongly encourage certain pretend play, for instance a toy kitchen with toy spatulas and frying pans. In such a case, the toys themselves (so to say) refer to the original practice, allowing one to smoothly enact the respective cooking activities in the pretense world, e.g., to prepare a mud pie. There are still other cases where pretend play consists in reenacting certain narrations, or narrative practices. Children are told, on TV and in children's books, grossly simplified stories about what knights, pirates, lions and bears do. Their pretend play can consist in reenacting those stories in roleplaying, e.g., being a "knight", and in making sense of oneself and one's surroundings from the perspective of the knight from the story. What matters is that pretense is always, but in a variety of different ways, related to social practices.

Finally, we acknowledge that there are also cases where children pretend play in what could only be called a rather creative way. This is a type of play that is novel or original, such as pretending that the teacups are dragons, pretending to engage in a sword fight during "dinner" play, or elaborating on a "lion" play by being a speaking lion or a lion that can drive cars. These seem like counterexamples to the ones discussed above, as there is seemingly no emulation taking place, the suggestion of how to play with objects is not followed, and the typical narratives are not upheld. However, such interpretation would be wrong. In creative play, children still relate to practices, albeit not the ones that are typical to that play. They simply borrow from other narratives (such as "dragons"), or emulate other practices (such as "driving"), which is what makes their play creative. Creativity is not to be defined by novelty or originality in the sense of unusualness, statistical rareness, or being detached from one's experiences. Creativity is also usefully conceptualized through the concept of flexibility with which one approaches a task, characterized by the ease with which someone changes between thoughts (Memmert \& Roth, 2007), and in our case, between practices. Hence, the new combination of themes from different, normally unrelated practices (e.g., "lion" + "car driving") can be regarded as creative. Creativity can then be understood not as the agent's inherent skill to think symbolically or counterfactually, but through interactions and immersion within a variety of sociocultural practices and a skill to flexibly shift between and combine them (Rucińska \& Aggerholm, 2019). Thus, we maintain that pretense is always related to social practices, even when pretense is very creative. 


\subsection{Differences between pretend play and ordinary engagements in social practices}

In order to comprehend pretense better, it is, however, also of importance to point out the differences between ordinary social practices and instances of pretend play. To our mind, there is not one key difference, but a variety of differences between them, varying with the different phenomena of pretense.

The most obvious difference between pretense and ordinary social practices is that the sense-making is often thematic in the case of pretense. In the context of ordinary engagements, the participants' attitude is characterized by the illusio (Bourdieu, 2000): the participants are normally not aware of the sense-making as sense-making. ${ }^{11}$ In pretense, by contrast, the sense-making is often explicitly visible. This can be seen, for instance, in the case of children who negotiate the rules of the world they enact, for example by proclaiming that a stick is a "horse" and not a "walking stick", or that a block toy is now an "apple", now an "orange".

What follows from this perspective is that it is not the case that adults in everyday life know reality and pretending children are the ones in danger of losing touch with it, and therefore, have to quarantine the reality from fiction. Quite to the contrary, ordinary participants of social practices are often characterized by the illusio and fail to understand their own contribution to the enaction of the world they experience, taking their social realities for granted. By contrast, pretending children are aware of the process of sense-making. They need not quarantine fiction from reality, because in the practice of play they have knowingly established new identities of objects and places through sense-making, without having to bypass the typical meanings of objects (see Rucińska, 2019). Of course, there are many different phenomena of pretend play, with different degrees of understanding the sense-making as sense-making. There might be cases where children become deeply absorbed in pretend play and are not able to step out of it at will, even when the play is not fun anymore or even when it becomes scary (Gendler (2011) termed this "emotional contagion"). The important point is that it is not pretending children, but adults who are in danger of being confused about the nature of the reality they are experiencing: they are in danger of being unaware of the sense-making as sense-making, and are thus at least in danger of taking the mind-dependent reality they enact in the context of social practices for an objective, mind-independent reality.

A further difference between the ordinary engagement in social practices and pretend play is that adults normally take the engagement in social practices very

\footnotetext{
11 According to Bourdieu, what we experience when we are immersed in action is a world of social relevance. What is counted as important in a particular practice is experienced as highly relevant. For example, students who are participating in the social practice of taking a test perceive the test as highly relevant. Bourdieu calls this attitude illusio, and speaks of social practices as a game that, from the inside of the game, "presents itself to someone caught up in it, absorbed in it, as a transcendent universe, imposing its own ends and norms unconditionally" (2000: 151). In enactivist words, even though humans are sense-makers and constantly enact worlds of practical significance, they are often not aware of the sense-making process as sense-making process, and are instead fascinated and captured by the contents of their experiences.
} 
seriously (especially in the illusio), while children's pretend play often happens in a spirit of fun. However, this is a difference in degree, not in kind. ${ }^{12}$ We acknowledge that sometimes children can take their play very seriously, just as adults can take engagements in social practices with a pinch of salt. Consider cases of adult pretend play such as engaging in historical re-enactments or paintball games where pretensewarfare is engaged in rather child-like ways. Playfulness can remain pivotal to a subset of adult pretense just as it is in child play.

However, the reason why children do not usually take their pretend play performances that seriously, and can remain in ludic state when pretending, which makes the sense-making process even more obvious to them, is that pretending children have not yet developed habitus systems. As described in Section 4, Bourdieu has coined the term habitus for systems of dispositions to make sense of the world. ${ }^{13}$ A habitus is always the result of prior interactions (2000: 148). Children's dispositions for enacting the world are not yet grounded in repeated social practices, which makes them much more flexible in shifting between them, and allows for them to be very creative in their play. They can easily make sense of their objective surroundings in ways adults with stable habitus systems cannot, but children also fail to see the rich and nuanced social reality, which adults with well-trained habitus systems routinely enact. While pretending children need at least some exposure to the norms of a social practice if they want to emulate it in pretend play, they need not yet master it. The formation of a complex habitus system is a gradual matter, which sometimes starts with emulating the adult in a joint engagement of pretend play. It is likely that pretense begins (ontogenetically) for children engaged in play with their parents and other adults, who introduce the pretense to their children.

A final difference between ordinary social practices and pretend play is the relation of the ordinary and pretense performances to the larger ordinary social practice. In the case of an ordinary performance of a social practice, the performance "clings" to the practice and carries it forward, having consequences in the social world. For example, if Lara performs badly in school, she will get a low grade, risk not obtaining her degree, and might not find a well-paid job in the future. By contrast, in pretend play many performances refer to and emulate ordinary social practices, but they do not have consequences going beyond the play. If Lara pretend plays to be a teacher and gives bad grades to her imaginary students, neither will this have bad consequences for the careers of the imaginary students, nor does the play have serious consequences for Lara's social reality. It might, however, have a therapeutic effect for her, and testing the boundaries of what it is to be a good teacher could enrich Lara's experiences. ${ }^{14}$

\footnotetext{
12 We would like to thank an anonymous reviewer for pointing this out, and for helpful examples and phrases we have made use of in the paragraph that follows.

13 If the respective dispositions are conceived of in the right way - that is, not as atomistic mechanisms waiting to be triggered, but rather as aspects of the self-organization of a dynamical system - all of this is perfectly consistent with enactivism.

14 There might of course be other rare cases where pretend play does indeed have consequences in the wider world: while playing "knights", someone might climb a façade, fall, and break her bones. A child might be made fun of during all of her interpersonal pretend play activities, and therefore be unable to develop a healthy self-conception even beyond the play. A politician might engage in her spare time in
} 


\subsection{Rethinking the role of the "pretense" concept}

There is only one point to add to this section's proposal of rethinking pretense. In Sect. 3, we argued that an analysis of the concept of pretense is only of rather limited importance for understanding the phenomena of pretense. However, we acknowledge that usages of the word "pretense" can also be an integral part of some social practices, and can make a difference to real-life phenomena. We turn to these cases below.

For instance, parents can classify and name the observed behavior of their children as "pretense" even when they have no verbal confirmation from the child if pretense was indeed his or her intention. Consider a situation where an 18-monthold child lifts up a banana to the ear and the parents comment "look at you pretending to have a phone!" Those parents who ascribe pretending to their children make use of the representationalist or intentionalist conception of pretense, even though from another perspective, those ascriptions might be over-projections. The practice of ascribing pretense is still helpful for communication and for the development of the child, and has important social functions, such as enculturating a child to what is acceptable and unacceptable behavior, even if it is misleading when regarded as part of a scientific theory of pretense. Sometimes such initially unjustified ascriptions of pretend play can even help children to start pretend playing, even though in other cases children might of course also be too young to really get the point.

The classification of an act as "pretense" can also be useful in other cultural contexts, where the pretender has to be aware of her pretense as pretense in order to be counted as a pretender - for example, in a context of pretending to be "Hamlet" in a Shakespearean play, or when pretending to be a bystander when in fact one is a private investigator. In these situations, the pretender is a participant of a habitus system that typically demands conceptual understanding of the situation as pretense.

To summarize, what matters dialectally is that we have proposed to re-conceptualize the explanandum of pretense. Praxeological enactivism opens up a new and differentiated perspective on pretense and allows for seeing it in a new light. That is, pretend play is not a mental representationalist phenomenon in the traditional sense of the term. It is rather a group of interrelated phenomena, which are all characterized by alternative ways of sense-making and by varying relationships to ordinary social practices, the eventual mastery of which is the raison d'être for pretend play. Still, pretend play is different from many ordinary participations in social practices because pretenders are often aware of the sense-making as sense-making, do not act from stable habitus systems, and do not have to fear that their pretend play has any consequences in the wider social world.

Footnote 14 (continued)

pretend play activities that are regarded as immoral, and lose her reputation. Thanks to an anonymous reviewer for this point. 


\section{The mind of the pretender}

In our praxeological enactivist re-description of pretend play, we have suggested that a core feature of the varying phenomena of pretense is alternative sensemaking. This ability to make sense of one's surroundings in such an alternative way seems to require certain mental states, like being able to imagine different possibilities for action, intending to act on them, or knowing that they differ from everyday forms of sense-making - mental states that so far we have not mentioned. One may wonder if the practice-focused theory of pretense we propose ignores the rich explanations of pretense found in philosophy and psychology that refer to the mind of the pretender. The opponents of ecological psychology (related to, but different from enactivism) characterize ecological psychology by "the credo [...] that postulating internal states has to be avoided at all costs" (Sebanz \& Knoblich, 2009: 1231). But this is certainly not true of enactivism, and in particular not of our version. We only insist that those "internal states" have to be conceived in the right way, namely as outward-directed. They must also be conceived of in terms of their contribution to the process of making sense of the surroundings, and not as selfcontained representations of them.

While this general strategy might sound fine, a critic might insist that we spell out in more detail how we conceive of these mental states. In anticipation of this critique, we will in this section refer to the typical cognitive capacities associated with pretense behaviors as found in the literature on pretense, including imagining that which is not real, knowing what is real while quarantining what is not real, and intending to pretend. We will show that it is a mistake to assume that enactivist theories cannot refer to these cognitive capacities to account for phenomena like pretense. On the contrary, we will show that these cognitive capacities are very much in line with enactivist cognitive science and can be at play in pretense, once understood in the light of our praxeological enactivism. The space limit does not allow for a full discussion of each of these cognitive capacities, but we will gloss over the approaches that enactivists can take towards these aspects of the mind of the pretender.

Firstly, imagination can have a place in an enactive account of pretense. Imagination is said to be needed to account for having controlled experiences in the absence of appropriate stimuli (Currie \& Ravenscroft, 2002). Enactivists can accommodate that thought, but they a) reconceptualize how to think of absences - instead of representing absent entities or scenarios in pretense, pretenders perceive novel, but just as present, affordances for actions, and b) explain that to perceive affordances in situations involves an act of prospecting or anticipating, which is imaginative in the relevant sense, while at the same time does not involve representational capacities.

To explain, when Joey is pretending that a box is a "car", he is not dealing with a situation where there is an absent car (as in the case where the car was just there but it was driven away), and when Sally is pretending to be a "lion", she is not dealing with an absent lion (as in the case where a lion just ran behind the bushes and is now gone). Joey and Sally are bringing forth, through the way they 
play, a world with a car or a lion. They do so by reenacting car scripts and "lion play" practices, for instance by making "vroom vroom" sounds or by "roaring". In more detail, they see affordances for such play in the situations, and the capacity for seeing affordances in situations is rooted in a situated sensorimotor, not a representational capacity (Rucińska, 2014). The playful affordance of an object in object-substitution play becomes present when one is in a play context and explores it in an embodied way. Similarly, the counterfactual situation in roleplay and imaginary play is afforded when one reenacts past experiences or creatively explores known cultural narratives.

Following the phenomenological understanding of the relationship between perceiving and imagining, these capacities should not be opposed to each other. Some phenomenologists propose that perception allows for possibilities of action to be perceived in the present object (Husserl, 1991; Heidegger, 1962: §17). Seeing such a possibility is anticipating something as happening. As the future anticipated action is not yet there, the anticipation can be seen as a kind of imagining itself (Casey, 1977). Husserl (1991), for instance, captured this as protention. Protention is a structural feature of the temporality of experience. It has been described as the implicit and unreflective anticipation of that which is just about to occur as experience progresses (Gallagher, 2013). Importantly, protention is not a mental act. Phenomenologists like Husserl and Heidegger emphasize that this future orientation is part of the structure of consciousness itself. On this view, perception is always imaginative (see Gallagher \& Rucińska, 2021). As protention involves an imaginary aspect, there is room to speak of imaginary processes as playing a role for enactivist pretending.

Enactivism also works with findings from neuroscience, where mental imagery is characterized not as a representational process, but as a motoric, bodily process involving neuronal activation and engaging bodily movements (Jeannerod, 1997; Driskell et al., 1994; Guillot et al., 2012; see Gallagher \& Rucińska, 2021). Available proposals for embodied and enactive imagination (Hutto, 2015; Hutto \& Myin, 2013, 2017; Ilundáin-Agurruza, 2017; Medina, 2013) treat imagination as a form of action that is strongly integrated with perceiving, involves implicit embodied sensorimotor processes, and is densely textured in a cross-modal (kinetic, tactile, kinesthetic and olfactory) way. Thus, the imaginative processes, including mental imagery, are seen by enactivists as grounded in embodied motor activations, which can further explain re-enactments in pretend play. As pretending involves not just implicit sensorimotor, but also explicitly embodied performances (Rucińska \& Gallagher, 2021), the complete explanation of pretend play will need to involve an account of how explicit movement further infuses our imaginings to trigger new motor schemas and allow alternative sense-making activities.

Secondly, some thinkers challenge the fact that imagination has any substantial role to play for pretense, focusing instead on the role of beliefs and intentions. For instance, Peter Langland-Hassan (2020) promotes the idea that pretend play can be explained through basic folk psychological attitudes like beliefs and intentions, without having to posit complex cognitive architectures (Nichols \& Stich, 2009) or sui generis imaginative states (Kind, 2013). Langland-Hassan argues that pretense can be reduced to a set of beliefs, desires and intentions. According to Langland-Hassan, pretending is to act with the intention to make $X Y$-like, 
while believing that $X$ will not be made into $Y$. For example, for Sally to pretend that she is a lion, Sally must - according to Langland-Hassan - intentionally make herself lion-like while believing she is not, or will not become, a lion.

To our mind, if the respective beliefs and intentions are conceived of in terms of deliberate, conscious states of mind, ascribing them to all pretend playing children would be an over-intellectualization. By contrast, if those beliefs and intentions are conceived of in a light-duty way, for instance in a purely dispositionalist way and not in terms of propositional attitudes (as suggested by Langland-Hassan himself), they would be compatible with praxeological enactivism. While enactivists might take issue with Langland-Hassan's reductive approach to pretense that does not bring in additional factors to its explanation beyond beliefs and intentions, such as social interactions, intersubjectivity, responding to affordances, or affect, enactivists are able to agree with him that pretense may involve beliefs and intentions, understood in his light-duty way. But still, we insist that the crucial explanatory processes of the phenomena of pretense are alternative sense-making and the emulation of social practices. We will now highlight some points where our praxeological enactivism can help to rethink the respective intentions and knowledge in pretend play.

Langland-Hassan writes that to make herself lion-like, Sally must know "some things about lions - that they walk on four legs, roar, and attack with their claws" (2020: 166), though admittedly, she does not need to know everything about lions. We agree that knowing what kinds of behaviors are lion-like does not require recalling salient features of lions. In our view, it involves recalling not just some facts about lions, but the pragmatic features of the lion play practice, that is, of how we usually portray lions. This is a form of knowing how to play lions. The knowledge being used for pretending that one is a lion is knowing how to enact "lion" scripts or narratives according to "lion play" practices, that is, a knowledge that comes from experiences - not necessarily experiences with actual lions, but with "lion play" practices, for instance when seeing how others play "lions".

Moreover, how I play to be a "lion" is emergent and negotiated in the play context, not determined in advance by what I know about lions. In pretending to be a "lion", I may be guided by what I remember about lions. If I have been in contact with a social practice of "lion-play", I may have formed respective dispositions for enacting a "lion world", which now can structure my play. But I may also be guided by the environmental opportunities for play. The chair in my living room affords a "lion hiding in a cave" play, but I may also be guided by how the people in my surroundings not just guide, but respond to my play (e.g., hearing my friend object by saying "no no, lions don't hide in caves, they climb up the trees!"), thereby jointly negotiating the rules of the play. Hence, both environmental opportunities and social affordances play a role in how my "lion" play unfolds.

Furthermore, my intention to play "lion" like that (being a "hiding lion" or "climbing lion") will be determined in the action, in response to the opportunities for action. It will also be mediated by my affective states: if I feel lazy, I will want to play to be a "hiding lion", and if I feel energetic, I might see the chair as affording being a "climbing lion". Intentions in action, understood not as discrete mental states that cause action, but re-conceptualized in sensorimotor and neuronal way as 
dynamic and context-sensitive processes underlying action initiation and maintenance (Uithol et al., 2014), have a place in an enactivist account of pretense.

In order to pretend to be a "lion", I may further need to know when I am in a play context, where lion-like behaviors are acceptable forms of engagement, and when I should step out of that play context. Such capacity could be seen as requiring of Sally a form of double knowledge of what is real and what is fictional, which, in turn, is seen as requiring quarantining fiction from reality, or pretense representations from true representations (Leslie, 1987). It could also be seen as requiring a form of double bookkeeping (Langland-Hassan, 2020), which "amounts to Sally's having and manifesting two different sets of dispositions: dispositions to act like a fiveyear-old girl (...) and dispositions to act somewhat lion-like (...)" (164). We agree with Langland-Hassan that engaging in pretense requires, in a way, to keep track of what is going on in the context of the pretense game, and recognizing that one is in that pretense context. Indeed, many of our social engagements require keeping track of what context we are in and what behavior is appropriate (see Rietveld, 2012 for an enactivist account of this capacity). We think that a play context is just another kind of context where certain forms of behavior can become appropriate. But we nonetheless have reservations about Langland-Hassan's claim that in pretend play, Sally "retains a background belief that she is not, and will not become, a lion in the process of these actions. That belief ensures that she has not lost her mind" (2020: 167). This claim suggests that some form of simultaneous tracking of reality (not being a real lion) and fiction (being a pretend "lion") is still needed. In our view, reality and fiction, or play and non-play contexts, need not be tracked simultaneously (see the discussion of the 'bypassing challenge' by Rucińska, 2019). They also need not be tracked in the mind of the individual pretender. All that needs to be tracked is when one is in a play context - a context where meanings can be negotiated - and that tracking most clearly occurs in intersubjective contexts.

We propose that social cues in joint play (following gaze and non-verbal cues, attuning to the other, or negotiating the rules of the play) allow one to track being in a play context, whereas in solitary play, the behaviors of marking and blocking (Rucińska \& Gallagher, 2021) allow one to further carve out and navigate the play space. ${ }^{15}$ It is therefore not just the belief that ensures that Sally has not lost her mind. As mentioned in Section 3, one could mistake reality for fiction due to emotional contagion, or get lost in the play and question if the newly created temporal playreality is here to stay. But Sally rarely does confuse the play for non-play contexts, thanks to the early-learned capacity to triangulate and intersubjectively attune to those others with whom she co-creates what counts as real. Following the enactivist take to co-creation of our reality and letting go of the idea of two "realities" occurring simultaneously in pretense (one real and one fictional), we propose that in a

\footnotetext{
15 Marking is a form of abbreviated moving or gesturing used in dance rehearsal, such as using a finger rotation to represent a whole sequence of movements. Blocking refers to the theatrical practice of positioning objects, props and actors for a particular scene to improve the rehearsal of a scene and facilitate the acting process. Both marking and blocking are practices taught to scaffold the actor's cognitive and pragmatic performance, such as remembering the sequence of action.
} 
specific timeframe, we co-create a reality that temporally affords one meaning relative to that context. In the timeframe of play, the pretend reality is the only salient one, and so a belief that "one is not, or will not become", the pretend entity, need not be entertained - definitely not as an occurrence, and not even as a behavioral disposition.

Thus, not only can enactivists refer to imagination, knowledge and intentions in order to account for pretense, they can also add a variety of new points to reconceptualize and better understand the imagination, intentions and knowledge that are involved in pretend play.

\section{Conclusion}

Human life is fundamentally shaped by the social practices humans are engaging in. Participation in social practices transforms how human beings make sense of their surroundings, and allows them to experience their surroundings differently in different contexts. Young children not only learn to master the sensorimotor contingencies of the physical world, but also to master the sociocultural contingencies of the social world. Pretend play is an essential step for young humans in this process of learning to navigate the worlds of social practices. Pretense, we have argued, is at root alternative sense-making, where the feature "alternative" is attributed from the perspective of an adult who participates in ordinary practices. Pretense is always related, though in varying ways, to social practices. Yet pretend play differs from many ordinary engagements in social practices by the fact that pretenders are often not in the illusio, but are aware of the sense-making as sense-making. Moreover, young pretenders do not act from stable habitus systems. And instances of pretense have normally no consequences in the wider social world.

This account of pretend play is made possible in virtue of our fusion of enactivism and praxeology into praxeological enactivism. By contrast, other approaches to pretense often detach an analysis of pretense from an analysis of its role in human life, that is, of its function of helping children to cope in a social environment consisting of a multitude of social practices. They are moreover often overly focused on a conceptual analysis of the concept "pretense" or on its folk psychological lay theories. Thereby, they end up with overly intellectualistic accounts of pretense, ones that a priori exclude certain acts as "genuine" acts of pretense (such as trying, imitating, or accidentally engaging in as-if behaviors) and exclude certain agents as "genuine" pretenders (e.g., on Leslie's or Rakoczy's account, 18-month-old children or animals cannot be counted as pretending agents). Against this background, we have aimed with our praxeological enactivism to not only provide an alternative new explanation of pretense, but to also fundamentally rethink the nature of pretense as an explanandum.

In sum, our praxeological enactivism provides new conceptual tools for explanations of pretense, and elucidates the importance of pretend play for the enculturation of children. We believe that our analysis can make a difference on how pretense is studied empirically, for instance, by encouraging longitudinal studies of pretense, which take into account the social practices that pretend play emulates, as well as 
the agent's individual history of engagements and the context within which she pretends.

Acknowledgements We would like to thank two anonymous reviewers for their very helpful comments on an earlier version of this paper. We would also like to thank the participants of the 2019 international conference on Pretend Play and E-Cognition in Antwerp, Belgium, for their input that shaped the ideas presented in this paper.

Funding Open Access funding enabled and organized by Projekt DEAL.

Open Access This article is licensed under a Creative Commons Attribution 4.0 International License, which permits use, sharing, adaptation, distribution and reproduction in any medium or format, as long as you give appropriate credit to the original author(s) and the source, provide a link to the Creative Commons licence, and indicate if changes were made. The images or other third party material in this article are included in the article's Creative Commons licence, unless indicated otherwise in a credit line to the material. If material is not included in the article's Creative Commons licence and your intended use is not permitted by statutory regulation or exceeds the permitted use, you will need to obtain permission directly from the copyright holder. To view a copy of this licence, visit http://creativecommons.org/licen ses/by/4.0/.

\section{References}

Austin, J. L. (1958). Pretending. Proceedings of the Aristotelian Society, Supplementary Volumes, 32, 261-278.

Anscombe, G. E. M. (1958). Pretending. Proceedings of the Aristotelian Society, Supplementary Volumes, 32, 279-294.

Bogdan, R. (2005). Pretending as Imaginative Rehearsal for Cultural Conformity. Journal of Cognition and Culture, 5(1-2), 191-213. https://doi.org/10.1163/1568537054068651

Bourdieu, P. (2000). Pascalian meditations. Stanford University Press.

Casey, E. (1977). Imagining and remembering. Review of Metaphysics, 31(2), 187-209.

Chemero, A. (2009). Radical embodied cognitive science. MIT Press.

Currie, G. (2004). Arts and minds. Oxford University Press. https://doi.org/10.1093/0199256284.001. 0001

Currie, G., \& Ravenscroft, I. (2002). Recreative minds. Oxford University Press. https://doi.org/10.1093/ acprof:oso/9780198238089.001.0001

de Jaegher, H., \& Di Paolo, E. (2007). Participatory sense-making. Phenomenology and the Cognitive Sciences, 6(4), 485-507.

Dennett, D. (2020). Comment on "Affordances in "Dennett's 'from bacteria to Bach and back"”. AVANT. The Journal of the Philosophical-Interdisciplinary Vanguard, 11(2). https://doi.org/10.26913/avant. 2020.02.14

Di Paolo, E. A., Cuffari, E. C., \& De Jaegher, H. (2018). Linguistic bodies. The continuity between life and language. MIT Press.

Driskell, J. E., Copper, C., \& Moran, A. (1994). Does mental practice enhance performance? Journal of Applied Psychology, 79(4), 481-492. https://doi.org/10.1037/0021-9010.79.4.481

Gallagher, S. (2013). Time in Action. In C. Callender (Ed.), The Oxford handbook of philosophy of time (pp. 420-438). Oxford Univ. Press.

Gallagher, S. (2017). Enactivist interventions: Rethinking the mind. Oxford University Press.

Gallagher, S., \& Rucińska, Z. (2021). Prospecting performance: Rehearsal and the nature of imagination. Synthese. https://doi.org/10.1007/s11229-020-02989-2

Gendler, T. (2011). Intuition, imagination, and philosophical methodology. Oxford University Press.

Guillot, A., Di Rienzo, F., Macintyre, T., Moran, A., \& Collet, C. (2012). Imagining is not doing but involves specific motor commands: A review of experimental data related to motor inhibition. Frontiers in Human Neuroscience, 6, 247. https://doi.org/10.3389/fnhum.2012.00247 
Harris, P. L., Kavanaugh, R. D., Wellman, H. M., \& Hickling, A. K. (1993). Young children's understanding of pretense. Monographs of the Society for Research in Child Development, 58(1), i. https://doi. org/10.2307/1166074

Heidegger, M. (1962). Being and time: Translated by Macquarrie, John; Robinson, Edward Schouten. HarperPerennial/Modern Thought.

Henrich, J. (2020). The weirdest people in the world: How the West became psychologically peculiar and particularly prosperous. Allen Lane.

Husserl, E. (1991). On the phenomenology of the consciousness of internal time (1893-1917): Translated by Brough, John B. Collected works. Kluwer Academic Publ.

Hutto, D. D. (2015). Overly enactive imagination? Radically re-imagining imagining. The Southern Journal of Philosophy, 53,68-89. https://doi.org/10.1111/sjp.12122

Hutto, D. D., \& Myin, E. (2013). Radicalizing enactivism: Basic minds without content. MIT Press.

Hutto, D. D., \& Myin, E. (2017). Evolving enactivism: Basic minds meet content. MIT Press.

Ilundáin-Agurruza, J. (2017). Muscular imaginings-A phenomenological and enactive model for imagination. Sport, Ethics and Philosophy, 11(1), 92-108. https://doi.org/10.1080/17511321. 2017.1294197

Jeannerod, M. (1997). The cognitive neuroscience of action. Fundamentals of cognitive neuroscience: [2]. Blackwell.

Kind, A. (2013). The Heterogeneity of the Imagination. Erkenntnis, 78(1), 141-159. https://doi.org/ 10.1007/s 10670-011-9313-z

Langland-Hassan, P. (2020). Explaining imagination (1st ed.). Oxford University Press.

Leslie, A. M. (1987). Pretense and representation: The origins of "theory of mind." Psychological Review, 94(4), 412-426. https://doi.org/10.1037/0033-295X.94.4.412

Lillard, A. S. (1993). Young children's conceptualization of pretense: Action or mental representational state? Child Development, 64(2), 372. https://doi.org/10.2307/1131256

Ma, L., \& Lillard, A. S. (2013). What makes an act a pretense one? Young children's pretend-real judgments and explanations. Child Development Research, 2013, 1-9. https://doi.org/10.1155/ 2013/467872

Medina, J. (2013). An enactivist approach to the imagination: Embodied enactments and "fictional emotions." American Philosophical Quarterly, 50(3), 317-335.

Memmert, D., \& Roth, K. (2007). The effects of non-specific and specific concepts on tactical creativity in team ball sports. Journal of Sports Sciences, 25(12), 1423-1432. https://doi.org/10.1080/ 02640410601129755

Nichols, S., \& Stich, S. P. (2009). Mindreading: An integrated account of pretence, self-awareness, and understanding other minds (Repr). Oxford cognitive science series. Clarendon Press

Perner, J. (1993). Understanding the representational mind (1st MIT Press pbk. ed.). Learning, development, and conceptual change. MIT Press

Picciuto, E., \& Carruthers, P. (2016). Imagination and pretense. In A. Kind (Ed.), Routledge handbooks in philosophy The Routledge handbook of philosophy and imagination (pp. 334-345). Routledge, imprint of Taylor \& Francis Group.

Rakoczy, H., Tomasello, M., \& Striano, T. (2005). How children turn objects into symbols: A cultural learning account. In L. Namy (Ed.), Emory cognition project series. Symbol use and symbolic representation: Developmental and comparative perspectives (pp. 67-97). Taylor and Francis.

Rietveld, E. (2012). Context-switching and responsiveness to real relevance. In J. Kiverstein \& M. P. Wheeler (Eds.), New directions in philosophy and cognitive science. Heidegger and cognitive science (pp. 105-135). Palgrave Macmillan.

Rucińska, Z. (2014). Basic pretending as sensorimotor engagement? In J. M. Bishop \& A. O. Martin (Eds.), Studies in applied philosophy, epistemology and rational ethics contemporary sensorimotor theory (Vol. 15, pp. 175-187). Springer International Publishing. https://doi.org/10.1007/ 978-3-319-05107-9_12

Rucińska, Z. (2016). What guides pretence? Towards the interactive and the narrative approaches. Phenomenology and the Cognitive Sciences, 15(1), 117-133. https://doi.org/10.1007/ s11097-014-9381-z

Rucińska, Z. (2017). The role of affordances in pretend play. In C. Durt, T. Fuchs, \& C. Tewes (Eds.), Embodiment, enaction, and culture: Investigating the constitution of the shared world (pp. 257277). MIT Press. https://doi.org/10.7551/mitpress/9780262035552.003.0015.

Rucińska, Z. (2019). Social and Enactive Perspectives on Pretending. AVANT. The Journal of the Philosophical-Interdisciplinary Vanguard. https://doi.org/10.26913/avant.2019.03.15 
Rucińska, Z., \& Aggerholm, K. (2019). Embodied and Enacted Creativity in Sports. In M. Cappuccio (Ed.), Handbook of embodied cognition and sport psychology (pp. 669-694). MIT Press.

Rucińska, Z., \& Gallagher, S. (2021). Making imagination even more embodied: Imagination, constraint and epistemic relevance. Synthese. https://doi.org/10.1007/s11229-021-03156-x

Schatzki, T. R., Knorr-Cetina, K., \& van Savigny, E. (Eds.). (2001). The practice turn in contemporary theory. Routledge.

Sebanz, N., \& Knoblich, G. K. (2009). Jumping on the ecological bandwagon? Mind the gap! European Journal of Social Psychology, 39, 1230-1233.

Steiner, P., \& Stewart, J. (2009). From autonomy to heteronomy (and back): The enaction of social life. Phenomenology and The Cognitive Sciences, 8, 527-550.

Thompson, E. (2017). Introduction to the revised edition. In F. J. Varela, E. Thompson, \& E. Rosch (Eds.), The embodied mind: Cognitive science and human experience (pp. xvii-xxxiii). London: MIT Press.

Uithol, S., Burnston, D. C., \& Haselager, P. (2014). Why we may not find intentions in the brain. Neuropsychologia, 56, 129-139. https://doi.org/10.1016/j.neuropsychologia.2014.01.010

Van Dijk, L., \& Rietveld, E. (2017). Foregrounding sociomaterial practice in our understanding of affordances: The skilled intentionality framework. Frontiers in Psychology, 7, 1969.

Varela, F. J., Thompson, E., \& Rosch, E. (1991). The embodied mind: Cognitive science and human experience. MIT Press.

Varela, F. J., Thompson, E., \& Rosch, E. (2017). The embodied mind: Cognitive science and human experience (Revised). MIT Press.

Weichold, M. (2016). Mastering socio-cultural contingencies: On extending the sensorimotor theory to the domain of culture. Journal of Consciousness Studies, 23(5-6), 203-227.

Weichold, M. (2017). Enacting the moral self: Combining enactivist cognitive science with mead's pragmatism. Pragmatism Today, 8(1), 146-172.

Weichold, M. (2018). Situated agency: Towards an affordance-based, sensorimotor theory of action. Phenomenology and the Cognitive Sciences, 17(4), 761-785.

Publisher's note Springer Nature remains neutral with regard to jurisdictional claims in published maps and institutional affiliations. 